\title{
Ocorrências de desastres naturais nos principais arranjos populacionais da Sub-região Leste do Nordeste brasileiro
}

\author{
Occurrences of natural disasters in major population arrangements Eastern subregion of \\ northeastern Brazil.
}

MARQUES, G. B.; SILVA, T. S.; MOURA, M. O.

guibm@hotmail.com;

\begin{abstract}
Resumo
Esta pesquisa tem como objetivo analisar os desastres naturais de origem hidrometeorológica e geológica e os danos associados nos principais arranjos populacionais da sub-região Leste do Nordeste brasileiro no período de 2003 a 2016. A partir das informações adquiridas através do Ministério da Integração Nacional foi possível quantificar os reconhecimentos dos desastres quanto ao tipo e a intensidade (Situação de Emergência - SE e Estado de Calamidade Pública - ECP). Criou-se um banco de dados com as informações sobre os principais espaços urbanos afetados e, em seguida elaborou-se a representação espaço-temporal dos desastres naturais. Foram verificados 152 registros de desastres hidrometeorológicos e geológicos nos espaços urbanos, dos quais $95 \%$ foram classificados como Situação de Emergência e 5\% como Estado de Calamidade Pública. O ano de 2011 destaca-se com o maior registro de desastres (28 registros). Por meio de consulta dos formulários disponíveis sobre os desastres (AVADAN E FIDE), constatou-se que 49 dos 152 registros ocorreram durante a estação chuvosa, isto é, $32 \%$ do total concentram-se nos meses de maior pluviometria da sub-região Leste. Os desastres registrados na região afetaram 124 mil pessoas e promoveram um prejuízo econômico próximo a 470 milhões de reais.
\end{abstract}

Palavras-chave: Desastres Naturais. Situação de Emergência. Estado de Calamidade Pública.

\begin{abstract}
This research aims to analyze the natural disasters of hydrometeorological and geological origin and their damage in the main population of the subregion arrangements East of northeastern Brazil in the period between 2003 until 2016. From the information collected through the Ministry of National Integration was possible to quantify the recognitions of the disasters as the intensity level (emergency situation and State of Public Calamity-ECP). Create a database with information on the main urban spaces affected and subsequently there was the space-temporal spatialization of natural disasters. 152 were verified records of hydro-meteorological and geological disasters in urban spaces, of which $95 \%$ were classified as emergency and $5 \%$ as a State of Public Calamity. The year 2011 stands out with the highest record of disaster (28 records). By querying the forms available on the disaster (AVADAN and FIDE), it was found that 49 of 152 records occurred during the rainy season, i.e. $32 \%$ of the total is concentrated in the months of highest rainfall of the sub-region East. The disasters registered in the region affected 124 thousand people and caused an economic loss close to $\mathrm{R} \$ 470$ million.
\end{abstract}

Keywords: Natural Disasters. Emergency Situation. State of Public Calamity.

\section{INTRODUÇÃO}

Os desastres naturais são aqueles causados por fenômenos e desequilíbrios da natureza, em especial, fenômenos de grande intensidade, agravados ou não pela ação humana, os quais podem implicar em perdas humanas ou outros impactos à saúde, danos ao meio ambiente, à propriedade, interrupção dos serviços e distúrbios sociais e econômicos (TOMINAGA, 2009; BRASIL, 2012). Com relação às origens dos desastres naturais esses podem ser de natureza geológica, hidrológica, meteorológica, climática e biológica, conforme a atual Classificação e Codificação Brasileira de 
Desastres Naturais - COBRADE, vigente na Instrução Normativa No 01, de 24 de Agosto de 2012 do Ministério da Integração Nacional (BRASIL, 2012).

Quanto as ocorrências dos desastres naturais deflagrados por eventos de chuvas excepcionais na Região Nordeste Moura et al.(2016) apresentam alguns exemplos registrados na região:

\begin{abstract}
No NEB, os desastres hidrológicos (enxurradas, inundações bruscas ou graduais e alagamentos) deflagrados por eventos de chuvas intensas (chuvas iguais ou superiores a $60,0 \mathrm{~mm} / \mathrm{dia}$ ) e de chuvas extremas (chuvas iguais ou superiores a $100,0 \mathrm{~mm} / \mathrm{dia}$ ) já foram registrados em cidades litorâneas da região norte do NEB, a exemplo de Fortaleza (ZANELLA, SALES e ABREU, 2009; OLÍMPIO $e$. al,. 2013), bem como em cidades litorâneas da Zona da Mata, setor leste da região, a exemplo de João Pessoa, Recife, Olinda e Maceió (CAVALCANTI, 2009; SILVA, 2014). Nessas cidades da Zona da Mata os eventos extremos de chuva deflagram também, desastres geológicos, do tipo deslizamento e erosão, devido a uma maior expressão dos tabuleiros litorâneos em seus sítios urbanos (MOURA et al., 2016. p.3).
\end{abstract}

Apesar da constatação de que os eventos pluviométricos deflagram desastres de ordem hidrológica, além também de poder deflagrar desastres do tipo deslizamento e erosão em algumas cidades do NEB, ainda não foi explorada a questão dos registros de desastres hidrológicos e geológicos associados às ocorrências dos eventos pluviais em uma escala mais ampla, ou seja, em escala regional.

As pesquisas existentes tratam a temática de forma pontual, através de estudos de caso, com pouca ou nenhuma conexão com a dinâmica da atuação dos sistemas atmosféricos e com os padrões sazonais das chuvas que caracterizam o NEB em distintas regiões homogêneas. Nesse sentido, ainda há uma lacuna quanto à compreensão da periodicidade dos eventos atmosféricos e seus danos ocasionados em diferentes escalas temporais (anual, sazonal e mensal) nos espaços urbanos das três regiões que mais definem o NEB quanto à distribuição espacial e temporal das chuvas, a saber: subregião Norte (NNEB) ou região semiárida, sub- região Leste (ENEB) ou Zona da Mata e sub-região Centro - Sul (SNEB).

A presente pesquisa tem como objetivo, analisar as ocorrências, os danos e a distribuição espaço-temporal dos desastres naturais de origem hidrometeorológica e geológica nos principais arranjos populacionais de médias e altas concentrações urbanas pertencentes ao limite territorial da sub-região Leste do Nordeste Brasileiro, no período de 2003 a 2016.

\title{
2. METODOLOGIA
}

A climatologia urbana se firma como área de saber de destaque no conhecimento dos impactos pluviais e suas repercussões nos espaços urbanos. O fomento teórico para a compreensão dessa problemática, em especial no Brasil, foi ofertado por Monteiro (1976, 2003, 2015) que propôs 
o Sistema Clima Urbano (S.C.U.). O S.C.U. é um sistema singular, aberto, evolutivo, dinâmico, adaptativo e possível de autorregularão que engloba o clima local e sua urbanização. Os níveis que formam a estrutura do S.C.U. podem ser representados por três canais de percepção humana: Canal I- Conforto Térmico, Canal II- Qualidade do Ar e Canal III- Impacto Meteórico que se associam, respectivamente, aos seguintes níveis de resolução do sistema: Subsistema I - Termodinâmico, Subsistema II - Físico-químico e Subsistema III - Hidrometeórico.

No tocante ao campo de aplicação dos estudos de clima urbano realizados no Brasil, ganharam destaque aqueles relacionados ao Subsistema Termodinâmico, principalmente os estudos relacionados às ilhas de calor e de frio, porém, a partir da década de 1990 ampliaram-se as pesquisas relacionadas ao Subsistema Hidrometeórico, já que as cidades passaram a ter sérios problemas relacionados ao impacto das chuvas, com alagamentos nas áreas de alta impermeabilização e deficiente infraestrutura nos sistemas de drenagem e com inundações em ambientes localizados próximos aos cursos d'água, principalmente rios e lagoas (ZANELLA; MOURA, 2013).

A análise dos desastres naturais deflagrados por episódios atmosféricos de grande intensidade e suas repercussões espaciais nos principais arranjos populacionais e concentrações urbanas do Nordeste ocorreu sob o viés teórico do Sistema Clima Urbano através do Subsistema Hidrometeórico proposto por Monteiro (1976, 2003, 2015). Esta proposta teórica é por excelência uma proposta geográfica, pois considera as relações sociedade e natureza em um espaço historicamente construído: o espaço urbano.

Quanto os procedimentos metodológicos da pesquisa realizaram-se levantamentos exploratórios das séries temporais dos registros de ocorrências de desastres hidrometeorológicos (inundações, enxurradas e alagamentos) e geológicos (deslizamentos, corridas de massa, subsidências e colapsos, erosão de margem fluvial e erosão continental) nas principais concentrações urbanas que integram a sub-região Leste do Nordeste entre o período de 2003 a 2016. A escolha dessa escala temporal se justifica em virtude de os registros mais consistentes das ocorrências dos desastres só estarem disponíveis no site do Sistema Nacional de Proteção e Defesa Civil (SINPDEC) do Ministério da Integração Nacional a partir do ano de 2003.

Com vista a uma melhor compreensão da variabilidade da precipitação na Região Nordeste, Alves (1997), Molion e Bernardo (2002) e Lucena (2008) estabeleceram uma divisão territorial que mais define a dinâmica da atuação dos sistemas atmosféricos e os regimes habituais da precipitação quanto à distribuição espacial nos meses mais chuvosos (Estação ou Quadra Chuvosa): sub-região Norte (NNEB) ou região semiárida, sub- região Leste (ENEB) ou Zona da Mata e sub-região Centro - Sul (SNEB). A área de estudo desta pesquisa é a sub-região Leste (ENEB) ou Zona da Mata, a 
qual engloba a parte oriental dos estados do RN, PB, PE e BA e o centro-leste de SE e AL. A estação chuvosa ocorre entre os meses de abril a julho (AMJJ) e o mês mais chuvoso é maio. Os sistemas mais atuantes no período chuvoso são: a ZCIT, as Ondas de Leste (OL) e os sistemas frontais, chamados aqui de Repercussões de Frentes Frias (RFF). Também atuam nessa sub-região o VCAS, os CCM, as LI e os sistemas de escala local: as brisas. Foi com base nessa divisão do NEB que ocorreu o enquadramento dos espaços urbanos que registraram desastres naturais associados à ocorrência de eventos de chuvas intensas e extremas

Os espaços urbanos que foram considerados na pesquisa são aqueles definidos pela nova proposta de classificação dos arranjos populacionais e concentrações urbanas do Brasil elaborado pela Coordenação de Geografia do IBGE (IBGE, 2015). O arranjo populacional é definido como "um agrupamento de dois ou mais municípios onde há uma forte integração populacional devido aos movimentos pendulares para o trabalho ou estudo, ou devido à contiguidade entre as manchas urbanizadas principais" (IBGE, 2015, p. 23). Assim, foram consideradas as médias concentrações urbanas e os arranjos populacionais com o número igual ou superior a 100 mil habitantes até o limite de 750 mil habitantes, além das altas concentrações urbanas e dos arranjos populacionais definidos a partir do limiar superior a 750 mil habitantes. A figura 1 mostra a distribuição dos espaços urbanos eleitos.

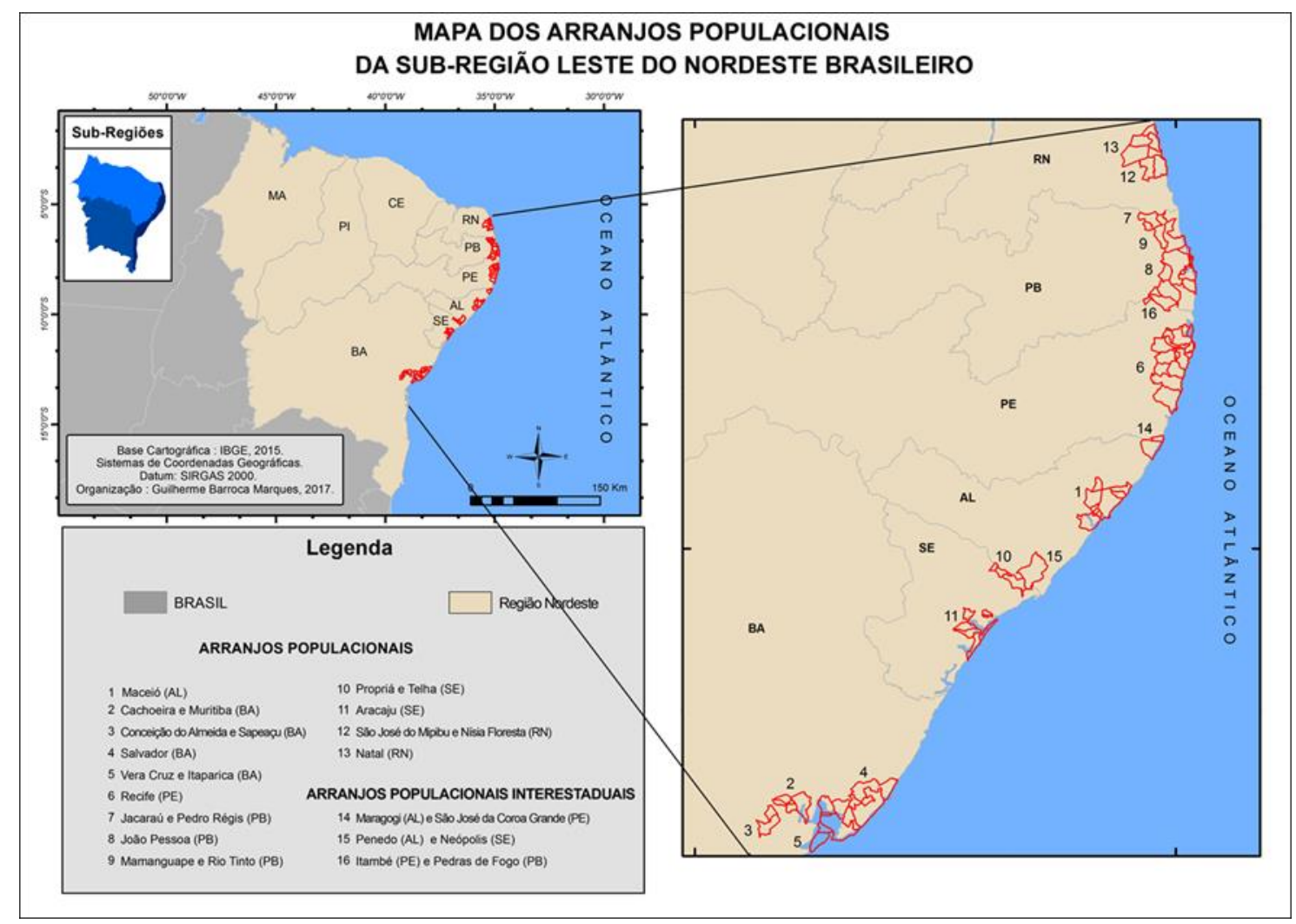

Figura 1 - Arranjos Populacionais da sub-região Leste. Fonte: IBGE, 2016. 
Para a identificação, frequência e intensidade dos desastres naturais ocorridos, serão utilizadas as portarias de reconhecimento de Situação de Emergência (SE) e as portarias de Estado de Calamidade Pública (ECP), fornecidas pelo Banco de Dados de Registro de Desastres, gerenciado pela Secretaria Nacional de Defesa Civil (SEDEC) disponíveis no site do Sistema Integrado de Informações sobre Desastres (S2ID). Também serão utilizados os formulários de Avaliação de Danos (AVADAN) e do Formulário de Informações do Desastre (FIDE) do Sistema Nacional de Proteção e Defesa Civil (SINPDEC), com o propósito de quantificar e analisar os danos humanos, materiais, ambientais, além dos prejuízos sociais e econômicos gerados em decorrência dos desastres naturais.

\section{RESULTADOS E DISCUSSÃO}

Nos espaços urbanos da sub-região Leste do NEB, entre 2003 a 2016, foi contabilizado um total de 152 desastres naturais, os quais foram oficialmente reconhecidos e publicados no Diário Oficial da União. Desse montante, 95\% (144 registros) foram reconhecidos por decretos de SE e $5 \%$ (7 registros) reconhecidos por decretos de ECP.

Em uma análise das ocorrências por Estado (gráfico 1), Pernambuco e Bahia apresentaram expressivo número de registros, 40 e 38 registros, respectivamente. Já o Estado com menor número de registros de desastres foi Sergipe (10 registros).

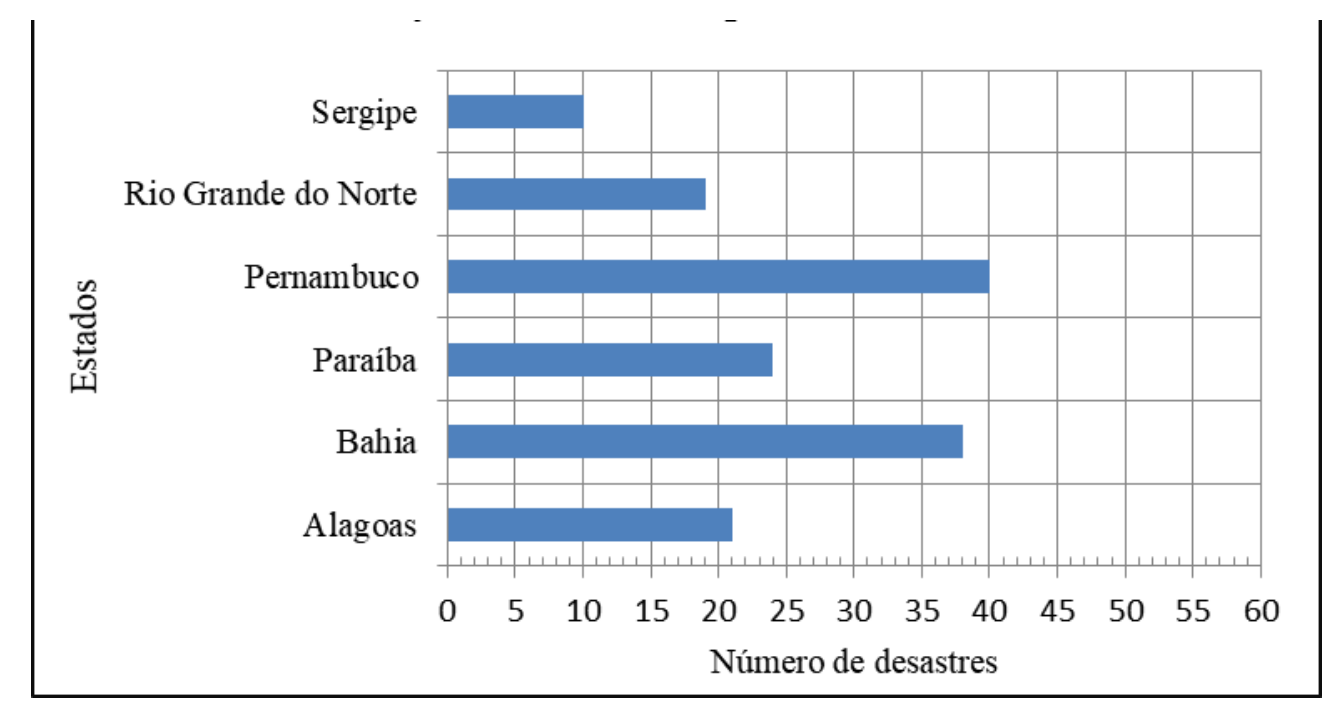

Gráfico 1 - Números de ocorrências de desastres naturais por Estado. Fonte: Brasil, 2016.

O gráfico 2 mostra a distribuição anual dos reconhecimentos por SE de ordem hidrometeorológica e geológica realizados entre 2003 a 2016. Observa-se que os anos de 20042010 e 2011 apresentaram o maior número de registros. 


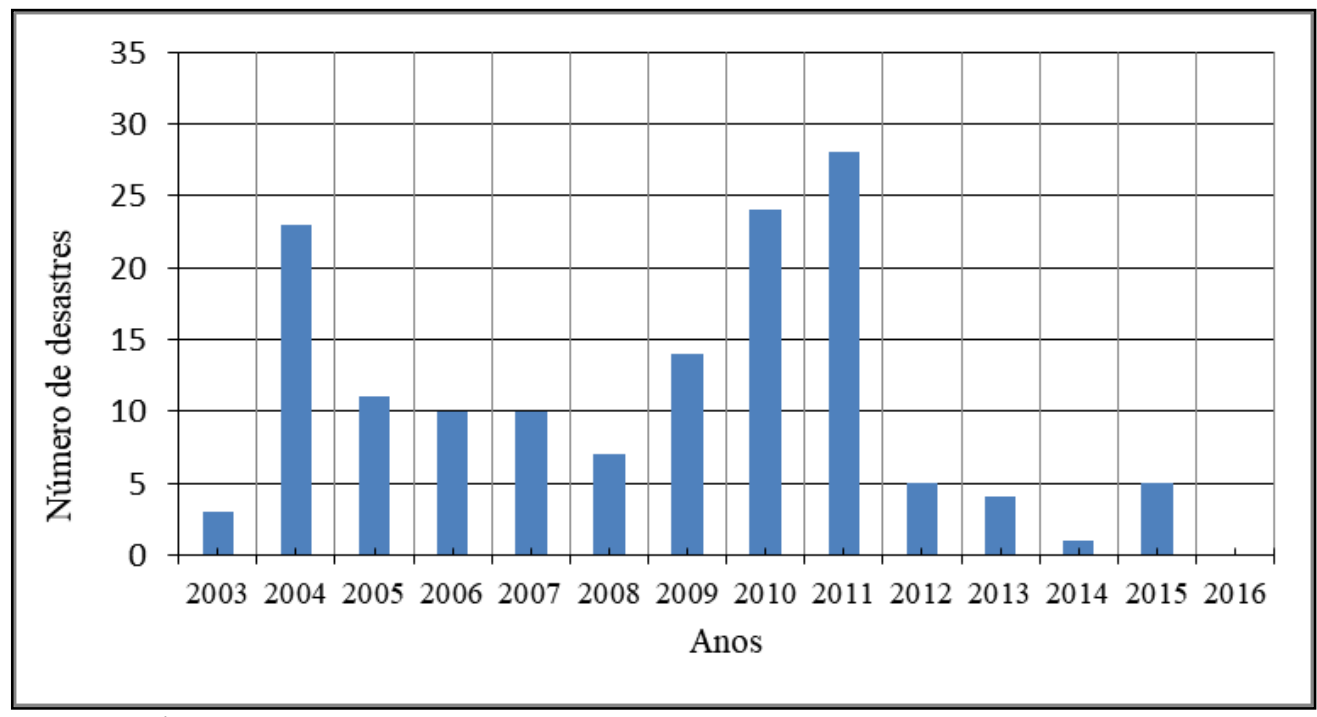

Gráfico 2 - Total anual dos reconhecimentos por SE. Fonte: Brasil, 2016.

No tocante aos tipos de desastres mais deflagrados (gráfico 3) com reconhecimentos por SE, verificou-se um maior número de desastres do tipo enxurradas (55 registros) seguido por chuvas intensas (28 registros). Com um número menor de registros aparecem os deslizamentos (seis registros) e as inundações (12 registros). Os desastres do tipo erosão de margem fluvial, corrida de massa, subsidência e colapsos não apresentaram registros.

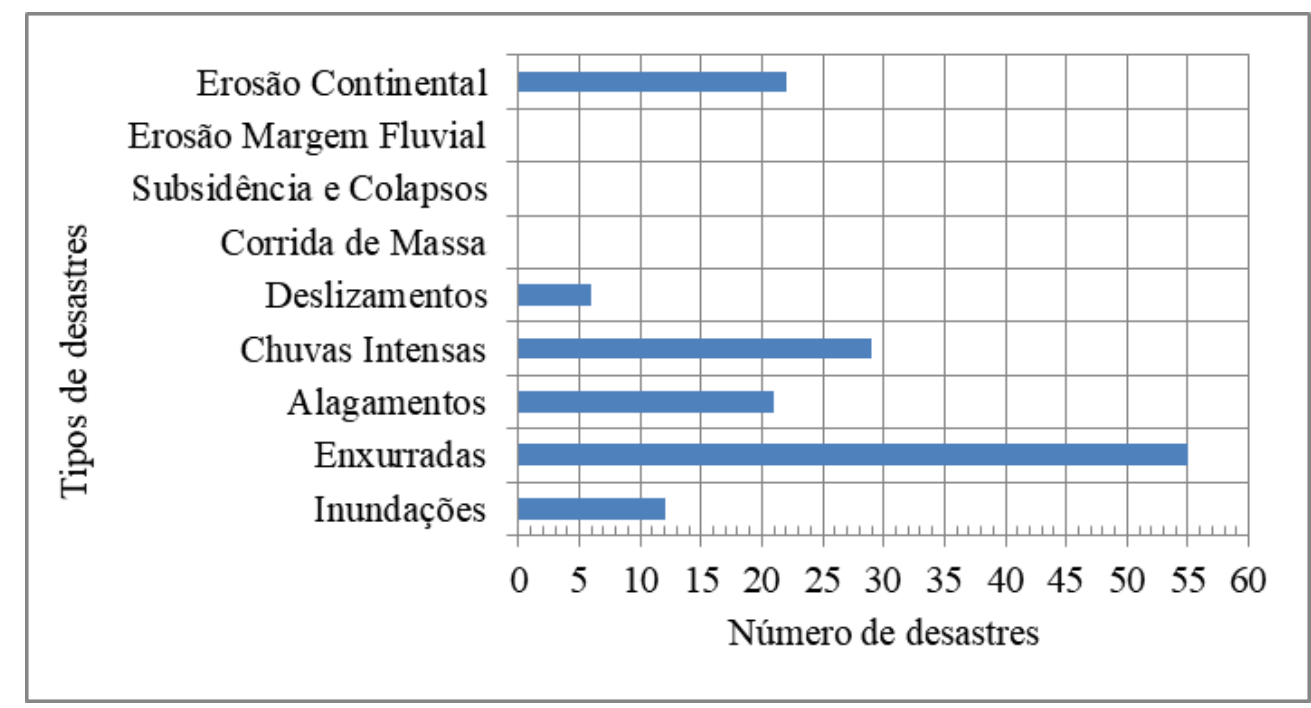

Gráfico 3 - Total dos tipos de desastres por reconhecimentos de SE. Fonte: Brasil, 2016.

Com relação aos registros de ECP (gráfico 4) verificaram-se apenas sete ocorrências em uma escala temporal de 14 anos, para todos os espaços urbanos estudados. Quanto aos tipos de desastres reconhecidos por ECP, constatou-se uma maior frequência de enxurradas (4 registros). Assim como nos registros por SE, nota-se uma maior frequência de alguns tipos de desastres que almejaram reconhecimento por ECP, a exemplo das enxurradas e das chuvas intensas. 


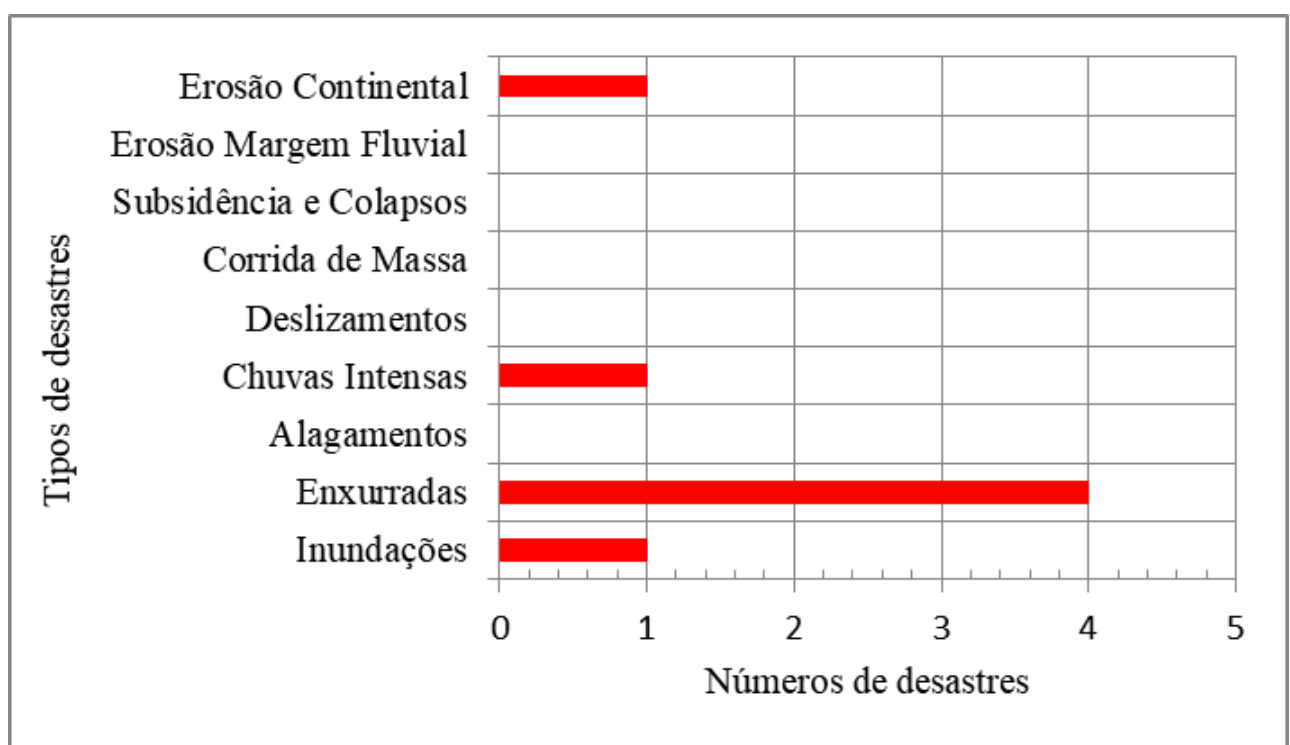

Gráfico 4 - Total dos tipos de desastres por reconhecimentos de ECP. Fonte: Brasil, 2016.

Uma ressalva faz-se necessária, no que tange às informações mais detalhadas dos casos registrados, apenas 39\% dos 152 casos registrados possuem formulários com informações completas. Ou seja, apenas 69 casos são passíveis de uma análise detalhada e suas consequências, como será exposto a seguir.

\subsection{Reconhecimentos de Situação de Emergência e Estado de Calamidade Pública por Arranjos Populacionais}

É importante salientar que nem todos os desastres naturais ocorridos tiveram seus danos devidamente catalogados pela Defesa Civil. Deste modo, os danos que serão apresentados estarão vinculados apenas aos formulários disponíveis sobre cada portaria de reconhecimento inerente a sua ocorrência. Dos 152 desastres naturais registrados, apenas 69 desastres possuíam formulário AVADAN ou FIDE.

Os arranjos populacionais com maiores registros de desastres foram Recife (22 registros) e Salvador (18 registros) conforme mostra o gráfico 5. Já os menores quantitativos, foram registrados nos arranjos populacionais de Pedras de Fogo (PB) /Itambé (PE), Vera Cruz - Itaparica, São José do Mipibu - Nísia Floresta e Conceição do Almeida - Sapeaçu com um registro cada. 


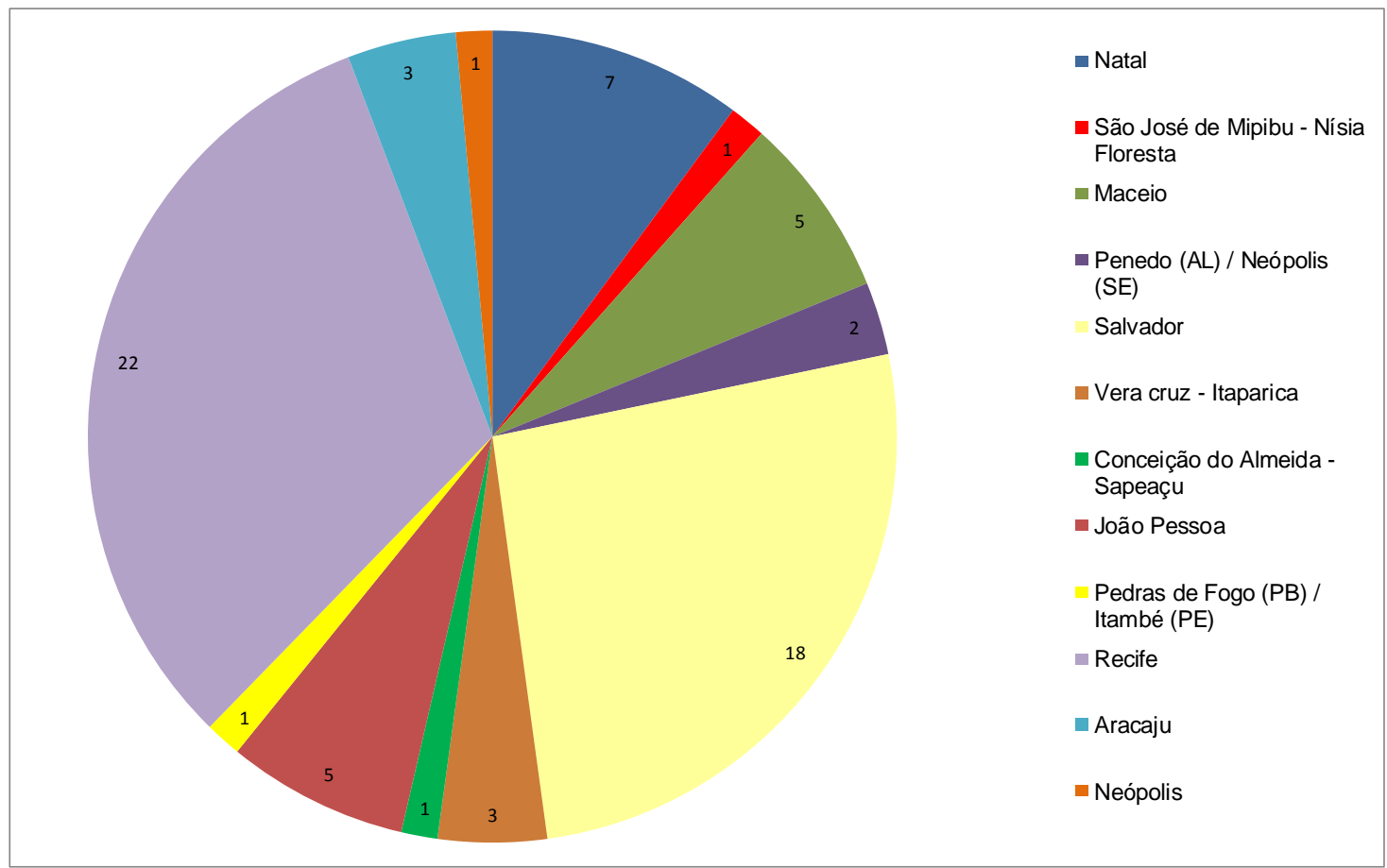

Gráfico 5 - Distribuição percentual dos desastres naturais por arranjos populacionais. Fonte: Brasil, 2016.

\subsubsection{Análise dos Danos Humanos}

Os danos humanos deflagrados por desastres naturais nos arranjos populacionais eleitos na pesquisa ultrapassam 124 mil pessoas afetadas, conforme mostra a tabela 1.

Tabela 1 - Total dos tipos de danos humanos deflagrados pelos desastres naturais nos espaços urbanos da sub-região Leste do NEB, 2003 a 2016. Fonte: Brasil, 2016.

\begin{tabular}{cc}
\hline Tipos de danos humanos & Número de ocorrências \\
\hline Mortos & 44 \\
Feridos & 444 \\
Enfermos & 3.199 \\
Desabrigados & 39.790 \\
Desalojados & 81.123 \\
Desaparecidos & 17 \\
Total & $\mathbf{1 2 4 . 6 1 7}$ \\
\hline
\end{tabular}

Observa-se um grande número de pessoas desalojadas (81.123 pessoas) e desabrigadas (39.790 pessoas). Registra-se também um elevado número de óbitos (44 mortes) e de desaparecidos (17 pessoas), números que apontam a gravidade dos desastres naturais registrados na área de estudo. 


\subsubsection{Análise dos Danos Materiais}

Os danos materiais, além de causar prejuízo financeiro, acarretam dificuldades no andamento das atividades diárias da população, como por exemplo, uma estrada danificada ou um hospital público destruído. As dificuldades também são estendidas ao setor privado, podendo ser alvo de prejuízos consideráveis. A tabela 2 mostra os danos materiais deflagrados pelos desastres naturais por tipo de unidade afetada e seus respectivos números de unidades destruídas e/ou danificadas.

Obras de infraestruturas públicas e estradas são as unidades com maiores montantes de destruição. É nítida a repercussão dos danos na esfera social. Com efeito, unidades habitacionais afetadas por desastres naturais somam mais de 33 mil, entre destruídas (29\% dos registros) e danificadas (71\% dos registros). Entre 2003 e 2016 os prejuízos causados nos municípios dos arranjos populacionais ultrapassaram as cifras dos $\mathrm{R} \$ 469.728 .919,00^{1}$.

Tabela 2 - Total dos danos materiais deflagrados pelos desastres naturais nos espaços urbanos da sub-região Leste do NEB, 2003 a 2016. Fonte: Brasil, 2016.

\begin{tabular}{|c|c|c|}
\hline Unidade Afetada & Destruída & Danificada \\
\hline Obras de arte (Unidade) & 138 & 525 \\
\hline Estradas (Km) & 138 & 1635 \\
\hline Pavimentação Vias Urbanas (Mil m2) & 16091 & 181068 \\
\hline Particulares de Saúde (Unidade) & 0 & 10 \\
\hline Particulares de Ensino (Unidade) & 0 & 12 \\
\hline Rurais/açude (Unidade) & 148 & 325 \\
\hline Industriais (Unidade) & 64 & 87 \\
\hline Comerciais (Unidade) & 29 & 2204 \\
\hline Instituições Públicas de Saúde & 0 & 196 \\
\hline Instituições Públicas de Ensino & 2 & 289 \\
\hline $\begin{array}{l}\text { Instituições Públicas Prestadoras de } \\
\text { Outros Serviços }\end{array}$ & 1 & 1 \\
\hline $\begin{array}{l}\text { Instituições } \\
\text { comunitário }\end{array}$ & 2 & 26 \\
\hline Unidades Habitacionais & 6838 & 26168 \\
\hline Obras de Infraestrutura Pública & 160 & 381 \\
\hline
\end{tabular}

\subsubsection{Danos Ambientais}

Os desastres naturais podem ocasionar elevada degradação ambiental tanto em áreas urbanas, quanto em áreas rurais. Com relação às intensidades dos danos, esses podem ser classificados conforme Instrução Normativa No 01, de 24 de agosto de 2012 do Ministério da Integração Nacional

\footnotetext{
${ }^{1}$ A Somatória parcial dos valores causados por danos materiais foi feita a partir dos valores disponíveis nos formulários de reconhecimento.
} 
(BRASIL, 2012). A tabela 3 apresenta os danos ambientais por níveis de intensidade inerentes aos desastres naturais deflagrados nos espaços urbanos da pesquisa.

Tabela 3 - Total dos danos ambientais nos espaços urbanos da sub-região Leste do NEB, 2003 a 2016. Fonte: Brasil, 2016.

\begin{tabular}{lccccc}
\hline \multicolumn{1}{c}{ ÁREAS AFETADAS } & $\begin{array}{c}\text { Sem } \\
\text { Danos }\end{array}$ & Baixa & Médio & Alta & $\begin{array}{c}\text { Muito } \\
\text { Alta }\end{array}$ \\
\hline Água Esgoto Sanitário & 31 & 0 & 7 & 5 & 4 \\
\hline Águas Efluentes Industriais & 44 & 0 & 1 & 0 & 0 \\
\hline Águas Resíduos Químicos & 44 & 0 & 1 & 0 & 0 \\
\hline Água outros & 41 & 0 & 0 & 2 & 3 \\
Solo Erosão & 20 & 4 & 7 & 9 & 8 \\
\hline Solo Deslizamento & 24 & 1 & 8 & 11 & 5 \\
Solo Contaminação & 42 & 1 & 2 & 2 & 0 \\
\hline Solo outros & 46 & 0 & 0 & 0 & 0 \\
Flora Desmatamento & 44 & 0 & 2 & 0 & 0 \\
\hline Flora Queimadas & 45 & 0 & 0 & 0 & 0 \\
Flora outros & 41 & 0 & 2 & 2 & 1 \\
\hline Fauna caça predatória & 44 & 1 & 0 & 0 & 0 \\
Fauna outros & 44 & 0 & 0 & 0 & 1 \\
\hline Total & $\mathbf{6 9 0}$ & $\mathbf{7}$ & $\mathbf{3 0}$ & $\mathbf{3 1}$ & $\mathbf{2 2}$ \\
\hline
\end{tabular}

Os danos ambientais apresentados no quadro 2 possuem um maior quantitativo para altas erosões do solo e deslizamentos (20 registros). Os registros de intensidade muito alta, também possuem relação com o solo. Os danos do tipo Erosões e deslizamentos somam 13 registros. Os processos erosivos, muito provavelmente, foram acentuados a partir de fenômenos meteorológicos, como chuvas intensas e extremas.

A figura 2 apresenta a distribuição total dos tipos de danos ambientais e suas categorias de intensidade, com exceção da categoria "sem danos", para uma melhor representação quantitativa das intensidades dos danos nas áreas afetadas.

Em uma ordenação percentual dos danos ambientais (Gráfico 6), constatou-se que os danos de baixa intensidade somam $8 \%$ do total dos danos.

Danos ambientais com intensidade muito alta apresentam $24 \%$ dos danos e de intensidade média representa 33\% dos danos. Já os maiores quantitativos dos danos ambientais ocorrem para a categoria intensidade alta, com $35 \%$ dos registros. 


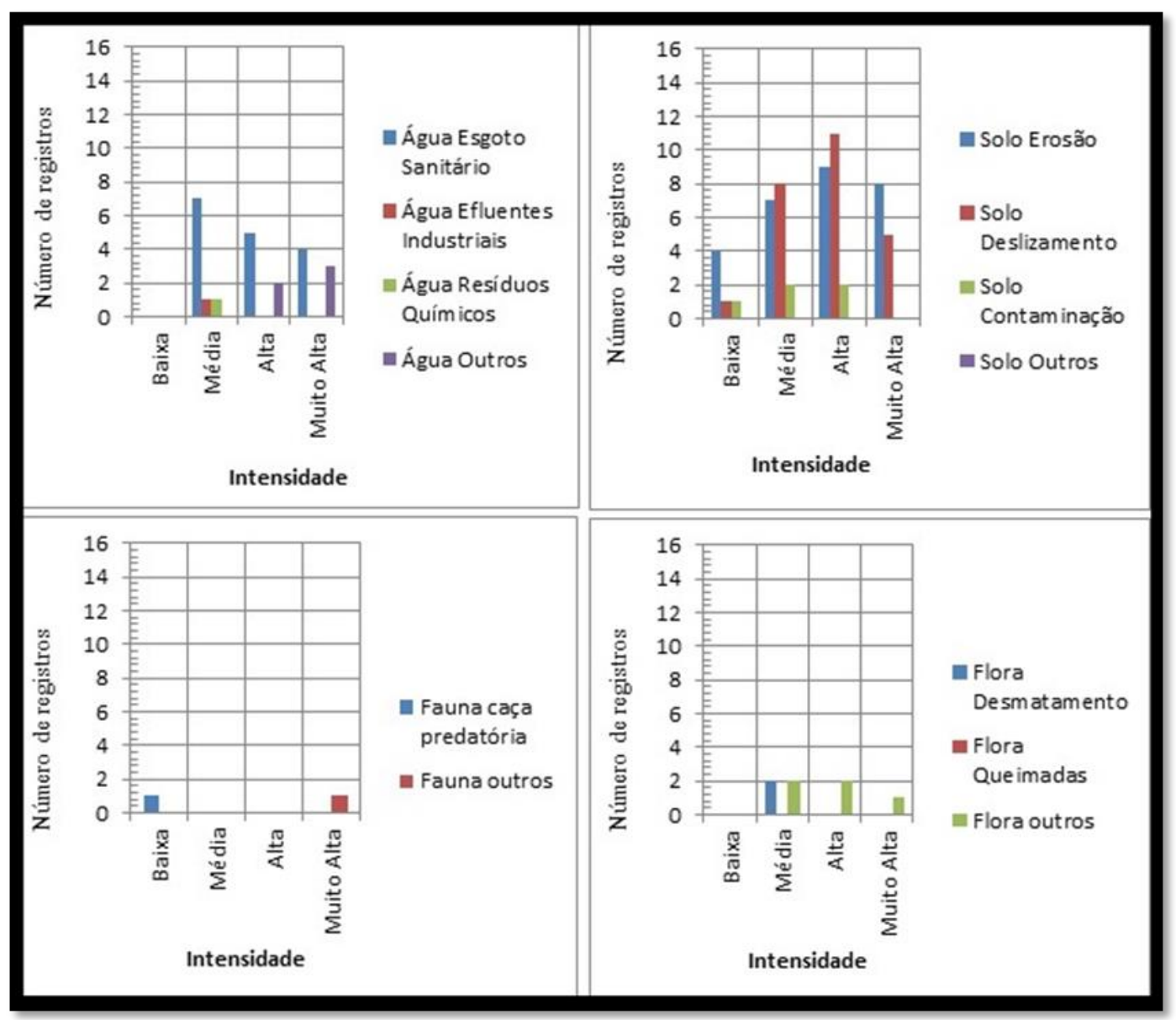

Figura 2 - Distribuição total da intensidade dos danos ambientais deflagrados pelos desastres naturais nos espaços urbanos da sub-região Leste do NEB, 2003 a 2016. Fonte: Brasil, 2016.

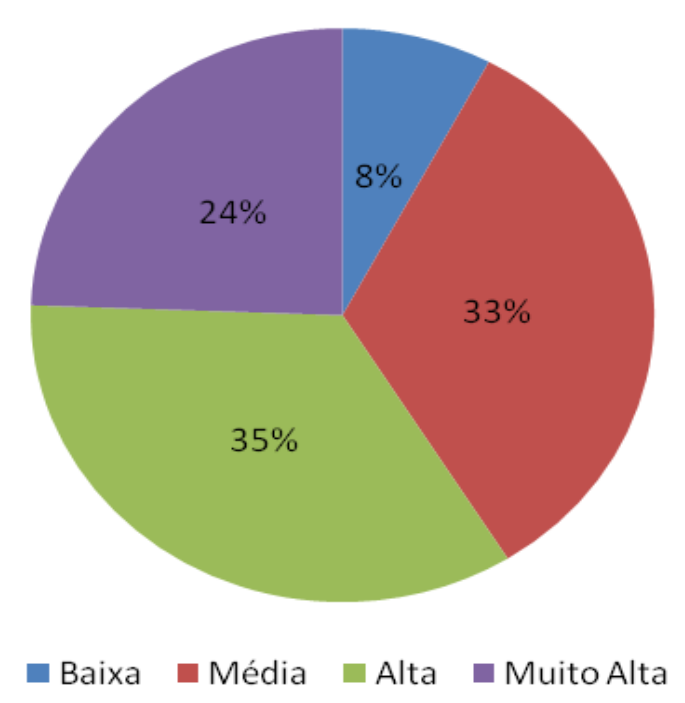

Gráfico 6 - Percentual total da intensidade dos danos ambientais. Fonte: Brasil, 2016. 


\section{CONSIDERAÇÕES FINAIS}

Foram obtidos importantes resultados sobre os desastres naturais de ordem hidrometeorológica e geológica nos espaços urbanos da sub-região Leste do Nordeste do brasileiro. De acordo com os dados expostos, 152 desastres naturais ocorreram nos espaços urbanos da região de estudo entre o período de 2003 a 2016, onde a maioria dos registros foi reconhecida por decretos de Situação de Emergência. Poucos foram os registros onde os desastres naturais de ordem hidrometeorológica e geológica alcançaram decretação de Estado de Calamidade Pública.

A frequência elevada de registros de desastres naturais mostra a ausência ou a fragilidade de gestão dos riscos de desastres. Em muitos municípios foram constatados os mesmos tipos de desastres naturais. A recorrência desses registros denuncia, portanto, o baixo grau de resiliência desses municípios, assim como servem para expor o seu grau elevado de vulnerabilidade socioambiental.

Os danos humanos registrados ultrapassam 124 mil pessoas afetadas. Ao passo que, os danos materiais chegaram à margem dos R \$ 469.728.919,00 de prejuízos (BRASIL, 2012). Não obstante, os danos ambientais foram mais intensos sobre o solo e as águas sanitárias, com intensos níveis de erosões e deslizamentos.

Por fim, esta pesquisa poderá contribuir com o desenvolvimento de outras investigações, a exemplo de pesquisas que investiguem os diferentes graus de vulnerabilidade socioambiental presentes nos territórios dos arranjos populacionais dos espaços urbanos da região estudada, bem como com estudos que abordem a dinâmica espaço - temporal dos eventos meteorológicos que deflagraram os desastres naturais identificados. Os resultados apresentados também poderão servir como inventário (banco de dados) para subsidiar possíveis planos de redução de riscos de desastres naturais na área de estudo da pesquisa.

\section{REFERÊNCIAS}

ALVES, J. M. B. Aspectos climatológicos do Nordeste brasileiro com ênfase a região semiárida: principais causas da variedade pluviométrica. In: Anais do $1^{\circ}$ Simpósio sobre Captação de Água de chuva no semiárido Brasileiro. Petrolina, PE, 17 - 21 de novembro de 1997. CD ROM.

BRASIL. Ministério da Integração Nacional. Anuário brasileiro de desastres naturais: 2013. Brasília: Ministério da Integração Nacional/Secretaria Nacional de Proteção e Defesa Civil/ Centro Nacional de Gerenciamento de Riscos e Desastres, 2014. Disponível em: http://www.mi.gov.br/c/document_library/get_file?uuid=fee4007a-ab0b-403e-bb1a8aa00385630b\&groupId=10157. Acesso em: 22 fev. 2017

BRASIL. Ministério da Integração Nacional. Instrução Normativa $\mathbf{n}^{0} 01$, de 24 de agosto de 2012 do Ministério da Integração Nacional, 2012. Disponível em: 
http://www.mi.gov.br/documents/10157/3776390/Instru_Normativa_01.pdf/8634a6e3-78cc-422aaa1d-7312ce7f1055. Acesso em: 25 Out. 2016.

CAVALCANTI, A. S. Avaliação de padrões atmosféricos associados à ocorrência de chuvas extremas no litoral da região Nordeste do Brasil: aspectos numéricos na previsão operacional do tempo. Tese. (Doutorado em Engenharia Mecânica). Rio de Janeiro: Programa de PósGraduação em Engenharia Mecânica/ UFRJ, 2009.

CEPED/ UFSC. Universidade Federal de Santa Catarina. Centro Universitário de Estudos e Pesquisas sobre Desastres. Atlas brasileiro de desastres naturais 1991 a 2010: volume Brasil. Florianópolis: CEPED/UFSC, 2012.

GONÇALVES, N. M. S. Impactos pluviais e desorganização do espaço urbano em Salvador. p. 6991. In: Clima Urbano. MONTEIRO, C. A. F; MENDONÇA, F. (Orgs.). São Paulo: Contexto, 2003.192p.

IBGE. Instituto Brasileiro de Geografia e Estatística. Arranjos Populacionais e Concentrações Urbanas do Brasil. Rio de Janeiro: Diretoria de Geociências/ Coordenação de Geografia, 2015. $167 p$. Disponível em: ftp://geoftp.ibge.gov.br/organizacao_territorial/arranjos_populacionais/arranjos_populacionais.pdf. Acesso em: 02 fev. 2016.

LUCENA, D. B. Impacto dos Oceanos Pacífico e Atlântico no Clima do Nordeste do Brasil. Tese. (Doutorado em Meteorologia). Campina Grande: Programa de Pós-Graduação em Meteorologia/ UFCG, 2008. 225p.

MOLION, L. C. B; BERNARDO, S.O. Uma revisão da dinâmica das chuvas no Nordeste brasileiro. Revista Brasileira de Meteorologia, Rio de janeiro, v.17, n.1, p. 1-10. 2002. Disponível em: http://www.rbmet.org.br/port/revista/revista_artigo.php?id_artigo=548 Acesso em: 05 fev. 2017

MONTEIRO, C. A. F. A Climatologia Geográfica no Brasil e a Proposta de um Novo Paradigma. p. 61-152. In: A Construção da Climatologia Geográfica no Brasil.MONTEIRO, C. A. F. (Org.). Campinas: Alínea, 2015. 194p.

MONTEIRO, C. A. F. Teoria e Clima Urbano. p. 9-67. In: Clima Urbano. MONTEIRO, C. A. F; MENDONÇA, F. (Org.). São Paulo: Contexto, 2003.192p.

MONTEIRO, C. A. F. Teoria e Clima Urbano. Série Teses e Monografias, $n^{\circ} 25$. São Paulo: Instituto de Geografia/USP, 1976.181p.

MOURA, M. O.; CUNICO, C; NOBREGA, R. S.; DUARTE, C. C. Desastres hidrometeorológicos na região Nordeste do Brasil: distribuição espaço - temporal dos reconhecimentos de Estado de Calamidade Pública. Caderno de Geografia., v.26, p.259 - 271, 2016.

OLÍMPIO, J. L. S; VIEIRA, P. M; ZANELLA, M. E; SALES, M. C. L. Episódios Pluviais Extremos e a Vulnerabilidade Socioambiental do município de Fortaleza: o episódio do dia 27/03/2012. Revista Geo UERJ, v. 1, p. 181-206, 2013.

OLIVEIRA, G. C. S; JUNIOR, J. P. S; NÓBREGA, R. S; GIRÃO, O. Uma Abordagem da Geografia do Clima Sobre os Eventos Extremos de Precipitação em Recife-PE. Revista Brasileira de Geografia Física, v. 4, n. 2, p. 238 - 251, 2011. 
SILVA, N. T. Precipitações diárias intensas na cidade de João Pessoa, Paraíba. Trabalho de Conclusão de Curso. (Curso de Bacharelado em Geografia). João Pessoa: Departamento de Geociências/ UFPB, 2014. 69p.

TOMINAGA, L. K. Desastres naturais: por que ocorrem? p.11-24. In: Desastres Naturais: conhecer para prevenir. TOMINAGA, L. K; SANTORO, J; AMARAL, R. (Orgs). São Paulo: Instituto Geológico, 2009.196p.

ZANELLA, M. E. Inundações em Curitiba: impactos, risco e vulnerabilidade socioambiental. 2. ed. Fortaleza: Editora da UFC, 2014. 197p.

ZANELLA, M. E.; MOURA, M. O. O clima das cidades do Nordeste brasileiro: contribuições no planejamento e gestão urbana. Revista da ANPEGE, v. 9, p. 75-89, 2013.

ZANELLA, M. E; SALES, M. C. L.; ABREU, N. J. A análise das precipitações diárias intensas e impactos gerados em Fortaleza-CE. GEOUSP- Espaço e Tempo, São Paulo, n 25, p 53-68, 2009.

Recebido em: 11/04/2018

Aceito para publicação em: 19/04/2018 